\title{
Absolutely Pure Gold with High Fineness 1000\%o
}

\author{
Z. Nikiforova ${ }^{(\bowtie)}$ \\ Diamond and Precious Metal Geology Institute SB RAS, Yakutsk, Russia \\ znikiforova@yandex.ru
}

\begin{abstract}
It is identified for the first time that, during process of complicated deformation in eolian conditions - mechanical transformation of flaky gold into toroidal form and then into globular-hollow form, gold is cleaned up to absolutely pure metal with fineness $1000 \%$. Note that, fineness of this eolian gold is higher than fineness of the reference object, shown by the detecting device (JXA-5OA micro-analyzer). In this connection, identified natural process of gold cleaning in eolian conditions can be successfully used in gold metallurgy to obtain absolutely pure gold.
\end{abstract}

Keywords: Gold $\cdot$ Fineness $\cdot$ Trace elements $\cdot$ Structures $\cdot$ Eolian process

\section{Introduction}

Native gold in exogenetic conditions, depending on its environment, undergoes gradual changes, in morphology and material composition. It is known that, gold cleaning in exogenetic conditions occurs mainly under chemical and physical-chemical influence in weathering crusts, and also as a result of simple strain in geodynamic conditions. This report will be focused on gold cleaning as a result of impact of mechanogenic processes in eolian conditions.

\section{Methods and Approaches}

Chemical composition of eolian gold of the Lena-Viluy interfluve (east Siberian platform) was studied by atomic-absorption spectrography (30 objects), spectral quantitative analysis (50 objects), and at JXA-5OA micro-analyzer (30 objects and 200 identifications).

\section{Results and Discussion}

During mechanical impact of sand grains on gold in eolian conditions, not only the form is transformed, but also inner structure and chemical composition are regularly changed. It is identified that, process of gold cleaning is more intensive in eolian conditions, than in hydrodynamic conditions (Nikiforova 1999). 
According to the analysis of eolian gold by atomic-absorption method, increase of gold fineness during transformation of flaky forms into globular-hollow forms from 810 to $970 \%$ is identified. Flaky gold with scarcely noticeable elevation at the periphery, has fineness range 810-970\%, with average gold fineness 890\%. In toroidal gold, interval of gold fineness fluctuation is identified - 920-970\%, with average index 940\%. Globular-hollow form is characterized by high gold fineness - 960-990\%, with average fineness $970 \%$.

Spectral quantitative analysis identified that, constant trace elements of flaky forms with characteristic features of eolian transformation are $\mathrm{Fe}-0,1 ; \mathrm{Pb}-0,003 ; \mathrm{Sb}-0,002$ $\mathrm{Cu}-0,017 ; \mathrm{Mn}-0,01 ; \mathrm{Pd}-0,002$; Ni-traces; Hg- traces. And some other. In toroidal gold, a smaller set of trace elements is identified Fe- 0,$1 ; \mathrm{Cu}-0,02 ; \mathrm{Mn}-0,03$; Ni- traces; $\mathrm{Hg}-$ traces, and in globular-hollow body only these trace elements are identified $-\mathrm{Fe}-0,1$; $\mathrm{Cu}-0,05 ; \mathrm{Mn}-0,001$.

Study of fineness of different areas of gold particles (Table 1 and Fig. 1) allowed identifying that, a flake with medium-grained structure (grain C-9a) has fineness from 747 t0 780\%o, and its more high-standard shell - from 950 to $988 \%$. Flake P-138 with partially recrystallized rim has gold fineness 900-970\%, and its central part 814-860\%. Fully recrystallized flake showed maximum gold fineness - 990-1000\%. Fineness of globular-hollow gold within one sample is not just high, but has an absolute value 1000\% . For example, 17 identifications in the grain 60a found insignificant fluctuations of fineness within interval 992-1000\%o, and 13 identifications in the grain 60b showed the highest gold fineness $-1000 \%$.

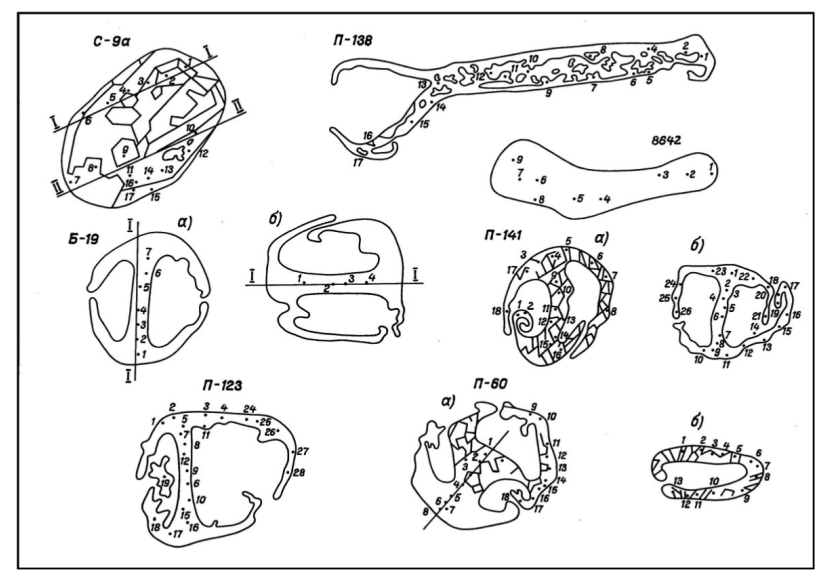

Fig. 1. Section of gold particles and points of fineness identification 
Table 1. Fineness of particular areas of gold particles, \%o

\begin{tabular}{|c|c|c|c|c|c|c|c|c|c|c|}
\hline \multirow{3}{*}{$\begin{array}{l}\text { Points of } \\
\text { fineness } \\
\text { measurement } \\
\begin{array}{l}\text { Index of the } \\
\text { sample }\end{array}\end{array}$} & \multicolumn{10}{|c|}{ Morphologic type of eolian gold } \\
\hline & \multicolumn{3}{|c|}{ Flaky } & \multicolumn{7}{|c|}{ Globular recrystallized } \\
\hline & C-9a & P-138 & 8642 & 6-19a & B-19б & P-141a & P-1416 & P-123 & P-60a & P-60б \\
\hline 1 & 759 & 973 & 998 & 903 & 860 & 990 & 997 & 1000 & 996 & 1000 \\
\hline 2 & 747 & 941 & 996 & 912 & 867 & $\begin{array}{l}\text { Not } \\
\text { identified }\end{array}$ & 992 & 955 & 996 & 1000 \\
\hline 3 & 759 & 933 & 998 & 907 & 869 & & 983 & 997 & 999 & 1000 \\
\hline 4 & 756 & Not identified & 984 & 904 & 919 & 990 & 991 & 999 & 1000 & 1000 \\
\hline 5 & 757 & 908 & 994 & 912 & & 988 & 985 & 996 & 999 & 1000 \\
\hline 6 & 755 & 920 & 997 & 902 & & 996 & 996 & 995 & 997 & 1000 \\
\hline 7 & 758 & 860 & 996 & 901 & & 980 & 987 & 1000 & 992 & 1000 \\
\hline 8 & 769 & 892 & 997 & & & 999 & 984 & 938 & 992 & 1000 \\
\hline 9 & 766 & 978 & 1000 & & & 980 & 970 & 930 & 999 & 1000 \\
\hline 10 & 953 & 814 & & & & 989 & 995 & 993 & 994 & 1000 \\
\hline 11 & 783 & 896 & & & & 994 & 985 & 997 & 1000 & 1000 \\
\hline 12 & 979 & 806 & & & & 993 & 995 & 995 & 1000 & 1000 \\
\hline 13 & 986 & 956 & & & & 990 & 987 & not identified. & 1000 & 1000 \\
\hline 14 & 970 & 937 & & & & 920 & 995 & & 1000 & \\
\hline 15 & 974 & 973 & & & & 932 & 1000 & 903 & 1000 & \\
\hline 16 & 988 & 974 & & & & 994 & 988 & 912 & 1000 & \\
\hline 17 & 970 & 900 & & & & 998 & 987 & 910 & 1000 & \\
\hline 18 & & & & & & 987 & 1000 & 1000 & 1000 & \\
\hline 19 & & & & & & & 998 & 999 & & \\
\hline 20 & & & & & & & 984 & Not identified & & \\
\hline 21 & & & & & & & 991 & & & \\
\hline 22 & & & & & & & 1000 & & & \\
\hline 23 & & & & & & & 983 & & & \\
\hline 24 & & & & & & & 996 & 1000 & & \\
\hline 25 & & & & & & & 998 & 1000 & & \\
\hline 26 & & & & & & & 999 & 1000 & & \\
\hline 27 & & & & & & & & 1000 & & \\
\hline 28 & & & & & & & & 1000 & & \\
\hline
\end{tabular}

It should be emphasized that, shell of globular-hollow forms constantly shows absolutely high fineness $1000 \%$. Just in several samples, primary gold preserved in partition, is characterized by lower fineness within a range from 860 to $919 \%$, for example grain $19 \mathrm{~b}$.

Increase of gold fineness in eolian conditions is explained by the fact that, as a result of complex deformation of flaky gold, very thin films of gold (fraction of $\mathrm{mcm}$ ) are formed, being overlapped on each other, generate a shell of globular forms. In addition, surface for active chemical interaction of metal with environmental elements is increased, that contributed to the maximum removal of silver and trace elements from primary gold particles.

It should be emphasized that, shell of globular-hollow forms constantly shows absolutely high fineness $1000 \%$. Just in several samples, primary gold preserved in 
partition, is characterized by lower fineness within a range from 860 to $919 \%$, for example grain $19 \mathrm{~b}$.

Increase of gold fineness in eolian conditions is explained by the fact that, as a result of complex deformation of flaky gold, very thin films of gold (fraction of $\mathrm{mcm}$ ) are formed, being overlapped on each other, generate a shell of globular forms. In addition, surface for active chemical interaction of metal with environmental elements is increased, that contributed to the maximum removal of silver and trace elements from primary gold particles.

The process of mechanically gold cleaning was proved by (Lechtman 1979) experimentally. According to the results of his experiments, clean layer of gold appeared after multiple alteration of forging of gold and copper alloy, with its processing in weak ammonia solution, where initial gold content did not exceed $12 \%$.

\section{Conclusions}

It is identified for the first time, that during complex deformation, when flaky gold is mechanically transformed into toroidal form and then into globular-hollow form, metal is cleaned to absolutely pure gold with fineness $1000 \%$. Identified natural process of gold cleaning in eolian conditionsB can be successfully used in gold metallurgy to obtain absolutely pure gold.

Acknowledgements. The work is implemented within scientific-research projects of Diamond and Precious Metal Geology Institute, Russian Academy of Sciences, project № 0381-20160004 .

\section{References}

Lechtman H (1979) A pre-Columbian technique for electrochemical replacement plating of gold and silver on copper objects. J Metals 31(12):154-160

Nikiforova ZS (1999) Typomorphic features of eolian gold. ZVMO. N5, pp 79-83

Open Access This chapter is licensed under the terms of the Creative Commons Attribution 4.0 International License (http://creativecommons.org/licenses/by/4.0/), which permits use, sharing, adaptation, distribution and reproduction in any medium or format, as long as you give appropriate credit to the original author(s) and the source, provide a link to the Creative Commons license and indicate if changes were made.

The images or other third party material in this chapter are included in the chapter's Creative Commons license, unless indicated otherwise in a credit line to the material. If material is not included in the chapter's Creative Commons license and your intended use is not permitted by statutory regulation or exceeds the permitted use, you will need to obtain permission directly from the copyright holder.

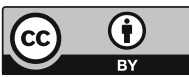

